\title{
Acesso e Sucesso no Ensino Superior em Portugal: Questões de Género, Origem Sócio-Cultural e Percurso Académico dos Alunos
}

\author{
Access and Success in Higher Education in Portugal: Issues of \\ Gender, Sociocultural Origin and Students' Academic Path
}

\author{
Leandro S. Almeida ${ }^{a^{*}}$, M. Adelina Guisande ${ }^{\mathrm{a}, \mathrm{b}}$, Ana Paula Soares ${ }^{\mathrm{a}}$, Luísa Saavedra ${ }^{\mathrm{a}}$ \\ ${ }^{a}$ Universidade do Minho, Braga, Portugal, ${ }^{b}$ Universidade de Santiago de Compostela, Santiago de Compostela, Espanha
}

\begin{abstract}
Resumo
Analisa-se o impacto do sexo e da origem sócio-cultural na nota de candidatura e nos cursos escolhidos no Ensino Superior, assim como nas dificuldades antecipadas e no rendimento académico no final do $1^{\circ}$ ano de frequência universitária. O estudo tomou 1407 estudantes da Universidade do Minho. Os resultados apontam que o sexo, a par do nível sócio-cultural das famílias, influencia a escolha de cursos (mais estudantes do sexo feminino e das classes mais desfavorecidas frequentam cursos de ciências sociais, ao passo que mais estudantes do sexo masculino e das classes mais favorecidas o fazem em cursos de engenharia). Verifica-se ainda que os estudantes do sexo feminino e mais favorecidos socialmente apresentam notas mais elevadas de candidatura ao Ensino Superior e na média no final do $1^{\circ}$ ano. Em relação às dificuldades antecipadas, os estudantes do sexo feminino e dos cursos de ciências sociais e económicas antecipam mais dificuldades interpessoais, enquanto os alunos do sexo masculino e a frequentar cursos de engenharia e de ciências económicas o revelam em relação à aprendizagem e à organização das tarefas diárias. A antecipação de dificuldades de aprendizagem relaciona-se ainda de forma negativa e estatisticamente significativa tanto com a nota de ingresso como com a média no final do $1^{\circ}$ ano.

Palavras-chave: Acesso ao ensino superior; sucesso académico; género; origem sócio-cultural.
\end{abstract}

\begin{abstract}
We analyse the impact of gender and sociocultural origin of freshmen from their college entrance exam scores and chosen undergraduate courses, as well the anticipation of difficulties in academic adaptation, and in academic success, at the end of their first year in college. The study's sample consists of 1407 freshman students from the Universidade do Minho. Results show that gender and sociocultural family background influence the courses that are chosen (most female students and students from less advantaged social class origins attended Social Science courses, whereas most male students and students from more advantaged social class origins attended Engineering courses). Higher sociocultural status and female students presented higher entrance exam scores and averaged better academic achievement at the end of their first year in college. Concerning anticipated difficulties, female students and students from Social and Economic Science courses anticipated more inter-personal difficulties, while male students and students from Engineering and Economic Science courses anticipated more difficulties in relation to learning and organizing daily activities. The anticipation of learning difficulties was associated in a negative and statistical way with entrance exam scores and academic achievement.

Keywords: Access to higher education; academic success; gender; sociocultural origin.
\end{abstract}

Nas últimas décadas, criadas as condições legais para a igualdade de oportunidades de acesso ao ensino, o centro das preocupações volta-se para as questões das desigualdades sociais no sucesso e na escolha dos diferentes percursos de formação, sendo certo que estes diferentes percursos assumem valorização diferenciada de acordo com os diplomas auferidos (Ball, Davies, David, \& Reay, 2001; Balsa, Simões, Nunes, Carmo, \& Campos, 2001; Duru-Bellat, 2000; Egerton \& Halsey, 1993; Machado, Costa, Mauritti, Martins, Casanova, \& Almeida, 2003). O Ensino Superior é, a este

\footnotetext{
Endereço para correspondência: Departamento de Psicologia, Instituto de Educação e Psicologia, Universidade do Minho, Campus Gualtar, 4719, Braga, Portugal. Fone: $351+253604241$, Ext.: 4255; Fax: 351 + 253678987. E-mail: leandro@iep.uminho.pt

Financiada por la Secretaría de Estado de Universidades e Investigación, Ministerio de Educación y Ciencia, España.
}

propósito, bastante ilustrativo. Segundo Balsa et al. (p. 43) "o momento de acesso ao ensino superior representa a última etapa de um processo ao longo do qual se produzem complexas formas de selecção sócio-cultural”. Em Portugal, por exemplo, as tomadas de decisão face ao Ensino Superior incluem, já no $9^{\circ}$ ano de escolaridade, um questionamento sobre a continuação dos estudos, o tipo de estudos a frequentar (de cariz mais profissionalizante ou mais orientado para o prosseguimento de estudos superiores) ou, até, o abandono do sistema de ensino/formação. Esta opção pode estabelecer-se, também, no final do $12^{\circ}$ ano, sendo certo que, para aqueles que pretendam ingressar no Ensino Superior, resta-lhes ainda decidir que tipo de curso e de instituição querem frequentar, ponderando as médias de acesso exigidas e as condições económicas da família.

Com efeito, estando o Ensino Superior em Portugal organizado por vários subsectores, as opç̃os dos alunos reflectem, 
como demonstra Gago et al. (1994), as condições sociais das famílias de origem e o valor sócio-cultural atribuído aos diplomas obtidos em cada um desses subsectores. Assim, o Ensino Superior público universitário é aquele que parece reunir as maiores preferências dos alunos, recebendo, proporcionalmente, mais alunos oriundos das classes sociais mais favorecidas e que apresentam trajectórias escolares mais positivas. É também a este subsector de ensino que os alunos atribuem mais prestígio e maiores probabilidades de inserção profissional (Braga da Cruz et al., 1995). Por sua vez, o Ensino Superior não-universitário recebe, proporcionalmente, mais jovens oriundos dos estratos sócio-económicos menos favorecidos e com percursos escolares mais empobrecidos.

A trajectória escolar dos alunos parece ter um impacto significativo no tipo de curso e estabelecimento de ensino que os alunos escolhem frequentar. Em geral, quanto mais elevado é o rendimento escolar, maior é a probabilidade do aluno se manter no sistema educativo, prolongando a sua escolaridade no tempo. Mas o aproveitamento escolar e a origem sócio-cultural interagem mutuamente, sendo a influência da origem sócio-cultural tanto maior quanto mais baixo for o aproveitamento escolar dos alunos. Como exemplifica Gago et al. (1994), se o rendimento escolar do filho de um operário e de um filho de um quadro médio forem baixos, o efeito de dissuasão para abandonar os estudos será maior para o filho do operário, pois os custos desse investimento são distintos em ambos os casos.

Desta forma, e apesar das taxas de frequência do Ensino Superior em Portugal terem aumentado significativamente nas últimas três décadas (Eurydice, 2003), a massificação deste nível de ensino não é sinónimo de igualdade de acesso para todos os jovens, continuando a registar-se acentuadas disparidades. Cabrito (2001) refere que as desigualdades sociais registadas nos anos 70 no Ensino Secundário tendem, actualmente, a verificar-se no Ensino Superior. O Ensino Superior parece funcionar, assim, mais numa lógica de reprodução do que de promoção sócio-cultural.

O impacto de factores escolares e sociais no acesso, frequência e sucesso no Ensino Superior tem sido verificado noutros estudos (Almeida, Vasconcelos, Machado, Soares, \& Morais, 2002; Braga da Cruz et al., 1995; Cabrito, 2001; Pinto, 2004; Saavedra, Almeida, Gonçalves, \& Soares, 2004), apontando Soares (2003) que o género e a classe sócio-cultural explicam $43 \%$ da variância dos resultados nas escolhas de cursos/áreas de formação que os alunos frequentam no Ensino Superior.

Neste contexto, e numa tentativa de explicação das taxas sócio-culturalmente diferenciadas no acesso e sucesso no Ensino Superior, vários autores consideram que as opções vocacionais em termos de carreira se constroem no seio de processos complexos que envolvem factores de ordem psicológica (interesses, aptidões, valores) e sócio-cultural (género, raça e classe sócio-cultural) (Duru-Bellat, 2000; Hansen, 2003; Reay, David, \& Ball, 2005; Surtees, Wainwright, \& Pharoah, 2002). Em certo sentido, poderse-ia afirmar que "as escolhas se efectuam dentro de "horizontes de acção' delimitados" (Ball et al., 2001, p. 68), por contextos, oportunidades e valores que jogam papéis diferenciados de sujeito para sujeito, e de grupo sócio-cultural para grupo sócio-cultural (Hatcher, 1998). Aprofundando esta questão, Balsa et al. (2001, p. 17) consideram que "o sistema mais insidioso de reprodução das posições é precisamente aquele que assenta numa sócio-culturalização do gosto e das aptidões pelas pertenças sociais, que fazem aparecer como 'naturalmente' diferenciadas opções que tendem a manter as posições de partida”. Dir-se-ia, então, que a par de uma vertente mais ou menos visível ou consciente de certos factores da tomada de decisão, existe uma outra vertente camuflada ou oculta que, guiando de uma forma aparentemente natural os interesses, os valores e até as aptidões, conferem um maior ou menor poder simbólico através do prestígio associado a certas escolhas.

A questão que se pode colocar passa então pela consciência que os alunos podem ou não ter do impacto desses factores no seu acesso e sucesso no Ensino Superior. Reay et al. (2005) referem a este propósito que os principais obstáculos apontados pelos estudantes ingleses das classes trabalhadoras são as dificuldades económicas, justificando a procura de uma actividade profissional paralela e a consequente falta de tempo para estudar (dois terços dos estudantes das classes mais desfavorecidas, contra apenas um terço dos estudantes da classe média repartiam a vida de estudante com a de trabalhador). Adicionalmente, os estudantes dos meios mais desfavorecidos apresentam escolhas mais limitadas em termos de cursos e de instituições do Ensino Superior.

Em Portugal a situação pode agudizar-se em face da maior concentração de famílias de recursos sócio-económicos mais baixos nas zonas periféricas e do interior do país, que podem não comportar os custos inerentes à frequência de uma Universidade posicionada nos grandes centros urbanos (Balsa et al., 2001). Por outro lado, a maior procura dos estabelecimentos universitários nas grandes cidades faz com que estes adquiram padrões mais elevados de excelência e, assim, atraiam os melhores alunos e, igualmente, os mais favorecidos sócio-culturalmente, reforçando ou adquirindo um maior prestígio sócio-cultural. Daí que, em Portugal como noutros países, apesar do número cada vez maior e mais diversificado de estudantes a frequentar o Ensino Superior, os estabelecimentos de ensino onde os estudantes mais desfavorecidos entram tendem a ser os de menor prestígio sócio-cultural, tornando-se necessário perguntar não só quem vai para a Universidade, mas antes "quem vai para onde" (Reay et al., 2005, p. 162).

A par destes factores de índole mais sócio-cultural, que condicionam grandemente o processo de tomada de decisão, a entrada na Universidade reveste-se ainda de profundas alterações na vida pessoal, académica e sócio-cultural dos estudantes. A chegada à Universidade implica, por exemplo, reformular relacionamentos interpessoais e familiares, estabelecer novas amizades, redefinir o papel de estudante, gerir tempos e actividades no quadro de uma maior autonomia, assistir a aulas magistrais e ter professores cuja relação é mais distante do que a estabelecida com os professores no Ensino Secundário (Almeida \& Soares, 2003; 
Almeida, Soares, \& Ferreira, 2001; Astin, 1993; Boyer, Coridian, \& Erlich, 2001; Chickering \& Reisser, 1993; Mercuri \& Polydoro, 2003; Pascarella \& Terenzini, 2005; Pereira, 2003; Vermetten, Vermunt, \& Lodewijks, 1999). Estas alterações podem desencadear maiores ou menores níveis de stress que, em certos casos, podem conduzir ao desajustamento, fracasso e abandono académicos.

Estas dificuldades não parecem independentes dos cursos frequentados. A novidade das matérias curriculares face ao Ensino Secundário é apontada como um dos factores das dificuldades da aprendizagem dos alunos (Boyer et al., 2001 ). Por outro lado, se o peso de aulas magistrais reforça o sentimento de anonimato face aos professores nos estudantes, a verdade é que estas parecem ser particularmente sentidas pelos alunos dos meios sociais mais desfavorecidos que percepcionam um maior desfasamento entre o seu meio de origem e a cultura do Ensino Superior. Ainda para estes autores, as alunas mostram-se mais organizadas na planificação do trabalho escolar e mais empenhadas em satisfazer as exigências do papel de estudante, muito embora apresentem menor confiança nas suas capacidades para lidar com as situações de avaliação e se revelem mais ansiosas.

Neste contexto, e tendo em conta a crescente massificação, e consequente heterogeneização sócio-cultural registada nos últimos anos no acesso e frequência do Ensino Superior em Portugal (Eurydice, 2003), importa conhecer a "nova" composição desta população, para que as instituições possam atender às suas características e necessidades. Neste sentido, o presente trabalho (inserido num projecto de investigação mais vasto financiado pela Fundação Calouste Gulbenkian) tomou como ponto de partida estudantes que ingressaram na $1^{\text {a }}$ fase do Concurso Nacional de Acesso ao Ensino Superior na Universidade do Minho e analisou o impacto do género e da sua origem sócio-cultural sobre a nota de candidatura (pondera as classificações no Ensino Secundário com os resultados nos exames de acesso), curso escolhido e classificações escolares no final do $1^{\circ}$ ano. Simultaneamente, analisam-se as dificuldades percepcionadas pelos estudantes na sua transição do Ensino Secundário para o Ensino Superior, fazendo esta análise em função do género, da origem sócio-cultural, da nota de acesso, do curso escolhido e do rendimento académico obtido.

\section{Método}

\section{Participantes}

Participaram neste estudo 1407 estudantes inscritos no $1^{\circ}$ ano dos cursos de licenciatura da Universidade do Minho (UM). A maioria da amostra é composta por elementos do sexo feminino (59\%), com idades compreendidas entre os 17 e os 57 anos de idade $(M=18.4 ; D P=1.83)$ e oriundos maioritariamente de classes com capital sócio-cultural desfavorecido ( $71 \%$ das mães e $72 \%$ dos pais não ultrapassam o $9^{\circ}$ ano de escolaridade). De referir ainda que a esmagadora maioria dos alunos frequenta o curso $(73 \%)$ e a Universidade $(76 \%)$ de $1^{\circ}$ opção, apresentando uma nota de candidatura à Universidade que oscila entre os 10.4 e os 19.2 valores $(M=14.6 ; D P=1.66)$.

\section{Instrumentos e Procedimentos}

Administramos uma Ficha de Identificação a todos os alunos que ingressaram na $1^{\text {a }}$ fase do Concurso Nacional de Acesso ao Ensino Superior nos cursos da UM. Os alunos foram informados dos objectivos do estudo e da confidencialidade dos resultados. Dos alunos inscritos na $1^{\text {a }}$ fase, $80 \%$ decidiram participar voluntariamente no estudo.

Nessa ficha, os alunos apontaram as dificuldades enunciadas que antecipavam na sua entrada na Universidade: relacionamento com os pares, relacionamento com os professores, aprendizagem e rendimento escolar, questões económicas, e organização e gestão das tarefas diárias. Em termos de rendimento escolar, tomámos a média das classificações dos alunos no final do $1^{\circ}$ ano fornecida pelos Serviços Académicos da UM.

Para a categorização da origem sócio-cultural dos estudantes recorremos às habilitações académicas do agregado familiar, formando três grupos de alunos: capital sócio-cultural baixo, formado pelos estudantes cujos pais possuem até ao $1^{\circ}$ ciclo do Ensino Básico (primeiros 4 anos de escolaridade) (31.3\%); capital sócio-cultural médio, constituído pelos estudantes cujos progenitores possuem entre o $5^{\circ}$ e o $12^{\circ}$ ano de escolaridade (40.1\%); e capital sócio-cultural alto, formado pelos alunos em que pelo menos um dos progenitores possuiu formação superior (28.6\%).

Adicionalmente, tomando em consideração a diversidade de cursos na amostra, procedemos à sua categorização em quatro grupos de acordo com a sua componente científica dominante: cursos na área de ciências naturais (12.8\%); cursos na área de ciências económicas (19.6\%); cursos na área de ciências sociais (30.2\%); e cursos na área de engenharias (36\%).

\section{Resultados}

A Tabela 1 apresenta a distribuição dos estudantes em cada uma das áreas de cursos consideradas em função do sexo e da origem sócio-cultural.

Tabela 1

Distribuição dos Estudantes em Função da Origem Sócio-Cultural e do Sexo por Agrupamento de Cursos

\begin{tabular}{lcccccc}
\hline $\begin{array}{l}\text { Origem } \\
\text { sócio-cultural }\end{array}$ & Sexo & $\mathrm{N}$ & $\begin{array}{c}\text { Ciências } \\
\text { naturais }\end{array}$ & $\begin{array}{c}\text { Ciências } \\
\text { económicas }\end{array}$ & $\begin{array}{c}\text { Ciências } \\
\text { sociais }\end{array}$ & $\begin{array}{c}\text { Engenharias } \\
\text { Baixa }\end{array}$ \\
& Masculino & $146(35.3 \%)$ & $13(31.7 \%)$ & $25(25 \%)$ & $23(16.1 \%)$ & $85(65.4 \%)$ \\
& Feminino & $268(64.7 \%)$ & $28(68.3 \%)$ & $75(75 \%)$ & $120(83.9 \%)$ & $45(34.6 \%)$ \\
\hline \multirow{2}{*}{ Média } & Masculino & $206(39.3 \%)$ & $23(29.5 \%)$ & $26(28.9 \%)$ & $27(16.2 \%)$ & $130(68.9 \%)$ \\
& Feminino & $318(60.7 \%)$ & $55(70.5 \%)$ & $64(71.1 \%)$ & $140(83.8 \%)$ & $59(31.2 \%)$ \\
\hline \multirow{2}{*}{ Alta } & Masculino & $191(50.9 \%)$ & $19(36.5 \%)$ & $30(41.7 \%)$ & $23(26.1 \%)$ & $119(73.0 \%)$ \\
& Feminino & $184(49.1 \%)$ & $33(63.5 \%)$ & $42(58.3 \%)$ & $65(73.9 \%)$ & $44(27.0 \%)$ \\
\hline
\end{tabular}


Como podemos constatar na Tabela 1, ocorrem algumas oscilações na distribuição dos estudantes cruzando as variáveis em análise. De uma forma geral, os estudantes do sexo feminino são mais oriundas das classes sócioculturais mais desfavorecidas, encontrando-se mais representadas nos cursos de ciências sociais e económicas. Aliás, uma análise do qui-quadrado $\left(\chi^{2}\right)$, revela que tanto o género como a origem sócio-cultural surge estatisticamente associados aos cursos escolhidos. Assim, tomando a variável sexo $\left(\chi^{2}=275.026 ; p<.001\right)$, verifica-se que $61.5 \%$ dos rapazes frequentam cursos de engenharia, enquanto que apenas $13.3 \%$ frequentam cursos de ciências sociais. Inversamente, as alunas predominam nos cursos da área ciências sociais (42.9\%), ficando bastante aquém nos cursos de engenharia (19.2\%). Também se observa uma associação estatisticamente significativa entre os cursos frequentados e origem sócio-cultural dos alunos $\left(\chi^{2}=26.720 ; p<.001\right)$. Os estudantes de famílias com níveis sócio-culturais mais reduzidos frequentam preferencialmente cursos de ciências sociais (34.4\%), enquanto que os alunos com uma origem sócio-cultural elevada se orientam predominantemente para os cursos de engenharia $(43.4 \%)$.

Na Tabela 2 apresentamos os resultados obtidos pelos estudantes na nota de acesso ao Ensino Superior e na média obtida no final do $1^{\circ}$ ano considerando o género e a origem sócio-cultural.
A leitura da Tabela 2 permite-nos constatar que, independentemente do género, a média de candidatura é tanto maior quanto mais alto for o nível sócio-cultural. Este efeito verifica-se igualmente, ainda que de uma forma menos acentuada, na média final do $1^{\circ}$ ano. Embora a análise de variância $\mathrm{F}$-Anova $(2 \times 3)$ realizada não tenha revelado um efeito de interacção entre as variáveis em análise, registouse um efeito principal da variável sexo $[F(1,1253)=$ $55.978 ; p<.001]$ e capital sócio-cultural $[F(2,1253)=$ $21.910 ; p<.001]$ na nota de candidatura de acesso ao Ensino Superior. Os estudantes do sexo feminino apresentaram notas de candidatura mais elevadas, enquanto que os estudantes dos níveis sócio-culturais mais favorecidos apresentaram resultados no acesso ao Ensino Superior mais altos.

Tal como a nota de candidatura, também a média das classificações no final do $1^{\circ}$ ano, se revela estatisticamente associada ao género e à origem sócio-cultural. No que diz respeito à variável sexo, o efeito principal $[F(1,1326)=$ 28.223; $p<.001]$ é também favorável aos alunos do sexo feminino. Por sua vez, no que concerne à origem sócio-cultural verifica-se também uma diferença estatisticamente significativa $[F(2,1326)=3.817 ; p<.05)]$ favorável aos alunos dos níveis mais favorecidos (muito embora nos testes de $S$ cheffe post-hoc não se tenham verificado diferenças com significado estatístico entre os três grupos em análise).

$\mathrm{Na}$ Tabela 3 apresentamos a distribuição das dificuldades antecipadas pelos alunos no momento de entrada no

Tabela 2

Médias, Desvios-Padrão e Leque de Variação dos Resultados na Nota de Candidatura e na Média Final do $1^{\circ}$ Ano em Função da Origem Sócio-Cultural e do Sexo

\begin{tabular}{|c|c|c|c|c|c|c|c|c|c|}
\hline \multirow[t]{2}{*}{ Origem sócio-cultural } & \multirow[t]{2}{*}{ Sexo } & \multicolumn{4}{|c|}{ Nota de candidatura (O-2O) } & \multicolumn{4}{|c|}{ Média final $1^{\circ}$ ano (O-2O) } \\
\hline & & $\mathrm{N}$ & $\mathrm{M}$ & DP & Mín.-Máx. & $\mathrm{N}$ & $\mathrm{M}$ & $\mathrm{DP}$ & Mín.-Máx \\
\hline \multirow[t]{2}{*}{ Baixa } & Masculino & 137 & 13.5 & 1.61 & $10.6-18.6$ & 147 & 12.2 & 1.40 & $10.0-16.2$ \\
\hline & Feminino & 251 & 14.5 & 1.43 & $10.4-19.0$ & 269 & 12.5 & 1.39 & $10.0-17.8$ \\
\hline \multirow[t]{2}{*}{ Média } & Masculino & 201 & 13.9 & 1.58 & $10.4-17.8$ & 212 & 12.1 & 1.35 & $10.0-17.0$ \\
\hline & Feminino & 311 & 14.7 & 1.60 & $11.0-18.7$ & 322 & 12.6 & 1.51 & $10.0-16.8$ \\
\hline \multirow[t]{2}{*}{ Alta } & Masculino & 180 & 14.7 & 1.84 & $10.5-19.2$ & 194 & 12.3 & 1.61 & $10.0-17.4$ \\
\hline & Feminino & 179 & 15.5 & 1.57 & $12.0-18.9$ & 188 & 12.9 & 1.67 & $10.0-17.5$ \\
\hline
\end{tabular}

Tabela 3

Distribuição dos Estudantes por Tipo e Número de Dificuldades Antecipadas em Função do Sexo, Nível Sócio-Cultural e Tipo de Curso Frequentado

\begin{tabular}{|c|c|c|c|c|c|c|c|c|c|c|}
\hline & & \multicolumn{2}{|c|}{ Sexo } & \multicolumn{3}{|c|}{ Origem sócio-cultural } & \multicolumn{4}{|c|}{ Agrupamento de cursos } \\
\hline \multicolumn{2}{|c|}{ Dificuldades antecipadas } & M & $\mathrm{F}$ & Baixa & Média & Alta & $\begin{array}{l}\text { Ciências } \\
\text { Naturais }\end{array}$ & $\begin{array}{c}\text { Ciências } \\
\text { Económicas }\end{array}$ & $\begin{array}{l}\text { Ciências } \\
\text { Sociais }\end{array}$ & Engenharias \\
\hline \multicolumn{2}{|l|}{ Económicas } & 30.8 & 34.4 & 43.3 & 35.4 & 17.5 & 32.2 & 34.8 & 36.9 & 29.4 \\
\hline \multicolumn{2}{|l|}{ Aprendizagem } & 24.1 & 12.7 & 19.9 & 15.1 & 19.3 & 14.4 & 21.4 & 10.1 & 22.9 \\
\hline \multicolumn{2}{|l|}{ Colegas } & 5.5 & 9.8 & 10.0 & 7.3 & 7.6 & 5.6 & 9.1 & 10.8 & 6.3 \\
\hline \multicolumn{2}{|l|}{ Professores } & 2.4 & 5.5 & 6.0 & 3.9 & 3.4 & 3.9 & 6.9 & 4.7 & 2.6 \\
\hline \multicolumn{2}{|l|}{ Tarefas } & 19.9 & 15.6 & 15.8 & 17.9 & 19.3 & 10.6 & 21.0 & 18.6 & 17.0 \\
\hline \multirow{3}{*}{$\begin{array}{l}\text { Número de } \\
\text { dificuldades }\end{array}$} & Nenhuma & 36.0 & 41.1 & 30.6 & 37.9 & 48.8 & 47.2 & 30.8 & 40.2 & 38.9 \\
\hline & Uma & 48.2 & 42.8 & 48.8 & 47.0 & 15.1 & 42.8 & 48.9 & 41.4 & 47.0 \\
\hline & Duas ou mais & 15.8 & 16.1 & 20.6 & 38.1 & 13.1 & 10.0 & 20.3 & 18.4 & 14.0 \\
\hline
\end{tabular}


Ensino Superior, considerando o género, a origem sóciocultural e o agrupamento de cursos frequentados. Por outro lado, atendendo ao facto de que não só o tipo de dificuldades mas também o seu número pode afectar os resultados, procedemos à categorização do número de dificuldades antecipadas pelos alunos em três grupos: nenhuma; uma dificuldade; e duas ou mais dificuldades.

A Tabela 3 permite-nos constatar que o tipo de dificuldades antecipadas pelos alunos parece variar em função do género, da origem sócio-cultural e do tipo de cursos frequentados pelos alunos. Os valores obtidos sugerem uma diferença com significado estatístico nalgumas das dificuldades percepcionadas segundo o género. Os rapazes antecipam, em maior percentagem, dificuldades na aprendizagem $\left(\chi^{2}=30.497 ; p<.001\right)$ e na organização das tarefas quotidianas $\left(\chi^{2}=4.356 ; p<.05\right)$, enquanto as alunas antecipam mais dificuldades nas relações com os colegas $\left(\chi^{2}=8.363 ; \mathrm{p}<.01\right)$ e no relacionamento com professores $\left(\chi^{2}=7.724 ; p<.01\right)$. A origem sócio-cultural influencia também de forma negativa e estatisticamente significativa a percepção de dificuldades económicas $\left(\chi^{2}=63.368 ; p<.001\right)$ e o número total de dificuldades antecipadas $\left(\chi^{2}=30.773\right.$; $p<.001)$. No que diz respeito à percepção de obstáculos económicos, $43.3 \%$ dos alunos com origem sócio-cultural baixa apontam esta dificuldade face aos $35.4 \%$ dos estudantes com origem sócio-cultural média e aos $17.5 \%$ com origem sócio-cultural alta.

Em relação ao total de dificuldades antecipadas, os estudantes do nível sócio-cultural mais baixo e médio aproximam-se na antecipação de uma única dificuldade, muito embora $38.1 \%$ dos alunos do grupo médio antecipem duas ou mais dificuldades (contra 20.6\% no nível mais baixo). Acrescente-se, ainda, que os estudantes do nível sócio-cultural mais elevado tendem a antecipar menos dificuldades ( $15.1 \%$ antecipam apenas uma dificuldade e $13.1 \%$ duas ou mais dificuldades).
No que concerne ao tipo de cursos, observam-se diferenças na percepção de dificuldades de aprendizagem $\left(\chi^{2}=30.261 ; p<.001\right)$, de relacionamento com os colegas $\left(\chi^{2}=8.237 ; p<.05\right)$, de relacionamento com os professores $\left(\chi^{2}=8.486 ; p<.05\right)$, de organização das tarefas diárias $\left(\chi^{2}=8.830 ; p<.05\right)$, bem como no número de dificuldades antecipadas $\left(\chi^{2}=20.749 ; p<.01\right)$. As dificuldades na aprendizagem são mais percepcionadas pelos estudantes de engenharia e de ciências económicas; as dificuldades no relacionamento com os colegas pelos alunos de ciências sociais e económicas; e as dificuldades no relacionamento com os professores e na organização das tarefas quotidianas pelos alunos de ciências económicas. Por último, são os estudantes de ciências económicas e sociais os que antecipam um maior número de dificuldades.

$\mathrm{Na}$ Tabela 4 apresentamos as médias e os desvios-padrão dos resultados obtidos pelos alunos na nota de candidatura de acesso ao Ensino Superior e na média no final do $1^{\circ}$ ano, considerando o tipo e o número de dificuldades antecipadas.

Os resultados obtidos sugerem que a nota de candidatura se encontra associada, de forma estatisticamente significativa, com o facto dos alunos anteciparem dificuldades económicas $(\mathrm{t}=2.556 ; p<.05)$, dificuldades de aprendiza$\operatorname{gem}(\mathrm{t}=2.105 ; p<.05)$ e dificuldades no relacionamento com os colegas $(\mathrm{t}=-2.858 ; p<.01)$. Os alunos que não antecipam dificuldades de tipo económico e de aprendizagem, assim como os alunos que antecipam problemas no relacionamento com os colegas apresentam uma nota de candidatura mais elevada. Por outro lado, considerando o número de dificuldades antecipadas pelos alunos, verificamos uma diferença estatisticamente significativa na nota de candidatura ao Ensino Superior $[F(2,1323)=5.666$; $p<$ $.01]$. Através dos testes post-hoc Scheffé verificamos que tal diferença ocorre de forma estatisticamente significativa quando comparamos o grupo que não antecipa qualquer dificuldade ou que antecipa duas ou mais dificuldades, face

Tabela 4

Médias e Desvios-Padrão na Nota de Candidatura e Média no Final do $1^{\circ}$ Ano segundo o Tipo e o Número de Dificuldades Antecipadas

\begin{tabular}{|c|c|c|c|c|c|c|c|c|}
\hline \multirow[b]{2}{*}{ Dificuldades anticipadas } & \multicolumn{4}{|c|}{ Nota de candidatura (O-2O) } & \multicolumn{4}{|c|}{ Média final $1^{\circ}$ ano $(0-20)$} \\
\hline & & $\mathrm{N}$ & $M$ & $D P$ & & $\mathrm{~N}$ & $M$ & $D P$ \\
\hline \multirow[t]{2}{*}{ Económicas } & Sim & 445 & 14.4 & 1.59 & Sim & 467 & 12.4 & 1.45 \\
\hline & Não & 881 & 14.6 & 1.69 & Não & 940 & 12.4 & 1.51 \\
\hline \multirow[t]{2}{*}{ Aprendizagem } & Sim & 228 & 14.3 & 1.75 & Sim & 245 & 12.1 & 1.35 \\
\hline & Não & 1098 & 14.6 & 1.63 & Não & 1162 & 12.5 & 1.51 \\
\hline \multirow[t]{2}{*}{ Colegas } & Sim & 113 & 15.0 & 1.56 & Sim & 113 & 12.8 & 1.39 \\
\hline & Não & 1213 & 14.5 & 1.66 & Não & 1294 & 12.4 & 1.50 \\
\hline \multirow[t]{2}{*}{ Professores } & Sim & 61 & 14.9 & 1.56 & Sim & 61 & 12.6 & 1.28 \\
\hline & Não & 1265 & 14.5 & 1.66 & Não & 1346 & 12.4 & 1.50 \\
\hline \multirow[t]{2}{*}{ Tarefas } & Sim & 228 & 14.7 & 1.70 & Sim & 244 & 12.6 & 1.57 \\
\hline & Não & 1098 & 14.5 & 1.65 & Não & 1163 & 12.4 & 1.47 \\
\hline \multirow{3}{*}{$\begin{array}{l}\text { Número de } \\
\text { dificuldades }\end{array}$} & Nenhuma & 510 & 14.7 & 1.64 & Nenhuma & 548 & 12.5 & 1.54 \\
\hline & Uma & 602 & 14.4 & 1.67 & Uma & 634 & 12.4 & 1.46 \\
\hline & Duas ou mais & 214 & 14.8 & 1.63 & Duas ou mais & 225 & 12.5 & 1.47 \\
\hline
\end{tabular}


ao grupo de estudantes que antecipa apenas uma dificuldade $($ diferença de média $=.28 ; p<.05$ e diferença de média $=$ $.36 ; p<.05$, respectivamente).

Finalmente, considerando o rendimento académico no final do $1^{\circ}$ ano, apenas se observam diferenças com significado estatístico quando se consideram as dificuldades na aprendizagem $(\mathrm{t}=3.480 ; p<.001)$ e as dificuldades no relacionamento com os colegas $(\mathrm{t}=-2.591 ; p<.01)$ antecipadas. Como seria esperado, os estudantes que anteciparam dificuldades na aprendizagem apresentam pior rendimento no final do $1^{\circ}$ ano, ocorrendo uma situação inversa relativamente àqueles que anteciparam dificuldades de relacionamento com os colegas.

\section{Discussão}

Centrando-nos nas questões levantadas acerca do acesso e sucesso no Ensino Superior Português, podemos dizer que os resultados deste estudo apontam para diferenças consideráveis, considerando o género, o capital sócio-cultural das famílias de origem e a qualidade do percurso escolar dos estudantes, na escolha do tipo de cursos a frequentar, na nota de candidatura e nas classificações escolares obtidas no final do $1^{\circ}$ ano do Ensino Superior. Estas mesmas variáveis parecem afectar, ainda, o tipo e o número de dificuldades antecipadas pelos alunos na transição do Ensino Secundário para o Ensino Superior.

Relativamente ao tipo de trajectos escolhidos, verificámos, numa lógica tradicional, e de forma consistente com outros estudos desenvolvidos no contexto nacional e internacional, que o género determina, em grande medida, uma predominância do sexo masculino nos cursos associados às engenharias e do sexo feminino nos cursos ligados às ciências sociais (Almeida et al., 2002; Balsa et al., 2001; Braga da Cruz et al., 1995; Castro \& Yamamoto, 1998; Gago et al., 1994; Machado et al., 2003; Reay et al., 2005; Soares, 2003). Estes resultados comprovam, de acordo com aquilo que é hipotetizado pelas teorias do domínio vocacional, uma influência do género nas escolhas educativas e/ou profissionais dos indivíduos e nas suas percepções de inserção sócioprofissional (e.g. Gottfedson, 1981; Lent, Brown, \& Hackett, 1994). Contudo, é de assinalar que apesar desta diferenciação, se assiste à frequência de mais mulheres nos cursos tradicionalmente associados ao sexo masculino do que de homens nos cursos tradicionalmente associados ao sexo feminino. Esta situação pode reflectir um efeito, registado a nível internacional, tanto de uma feminização no acesso e frequência deste nível de ensino (Almeida et al., 2002; Balsa et al., 2001; Braga da Cruz et al., 1995; Eurydice, 2003; Soares, 2003), como de uma maior flexibilidade e abertura das mulheres para cursarem programas de estudo menos tradicionais (Betz \& Hackett, 1997; Dawson-Threat \& Huba, 1996; Gianakos \& Subich, 1988; Hackett, Betz, Casas, \& Rocha-Singh, 1992; Lackland \& DeLisi, 2001).

Paralelamente, o capital sócio-cultural familiar conduz aqueles com menores recursos culturais e sociais a escolherem cursos onde o prestígio sócio-cultural é menor (tais como os cursos de ciências sociais), enquanto que os alunos detentores de maior capital económico, social, cultural e simbólico se direccionam, preferencialmente, para cursos nas áreas das engenharias e das ciências naturais. Desta forma, Machado et al. referem (2003) que "os estudantes provenientes de classes de maiores recursos distribuemse de forma totalmente homóloga a essa distribuição de capital simbólico, contribuindo, dessa forma, para a reproduzir" (p. 67). Estes dados são também consistentes com outros estudos conduzidos a nível nacional (Balsa et al., 2001; Braga da Cruz et al., 1995; Cabrito, 2001; Gago et al., 1994; Soares, 2003), o que leva Machado et al. (2003, p. 58) a afirmarem que existe no Ensino Superior um "duplo padrão de recrutamento de classe” jogando-se, simultaneamente, a reprodução e a mobilidade sócio-cultural que tanto pode ser total como englobar "trajectórias estacionárias com promoção escolar”.

Seguindo a linha de pensamento de Egerton e Halsey (1993) na caracterização da história do acesso ao Ensino Superior no século XX, dir-se-ia que em Portugal, tal como noutros países da Europa (Duru-Bellat, 2000; Reay et al., 2005) e no Brasil (Pinto, 2004), se assegurou uma igualdade de género quanto ao acesso e sucesso neste nível de ensino, mas não quanto ao processo. Com efeito, os estudantes do sexo feminino continuam a orientar as suas decisões para domínios de menor capital simbólico. E se, no que concerne às classes sociais, se tem vindo a verificar uma democratização do acesso, que permite a sectores mais deficitários, ao nível do capital sócio-cultural, colocar os seus filhos no Ensino Superior, o desfasamento entre o nosso País e os restantes membros da União Europeia é, ainda, muito acentuado (Eurydice, 2003). Sendo assim, tudo leva a crer que a expansão do Ensino Superior aumentou as oportunidades no acesso para um número cada vez maior de estudantes, mas as configurações do processo (que se reflecte nas escolhas e na forma como é vivenciada a transição para a Universidade) e do sucesso ainda se encontram diferenciadas por classe social e género. A existência deste efeito global traduz, assim, não só a forte influência do género na escolha de cursos deste nível de ensino, como a ideia que Ensino Superior é um sistema estratificado e onde as classes mais favorecidas continuam a ter acesso privilegiado aos lugares mais prestigiados e concorridos do sistema.

Por outro lado, e tendo em conta os dados obtidos ao nível da nota de candidatura ao Ensino Superior, bem como nas classificações obtidas no final do $1^{\circ}$ ano, afigura-se cada vez mais claro o quadro que aponta para um nível superior de rendimento académico dos elementos do sexo feminino e dos meios sócio-culturais e económicos mais favorecidos (Boyer et al., 2001; Reay et al., 2005). Os rapazes provenientes de famílias com recursos mais reduzidos encontram-se no extremo oposto desta hierarquia. $\mathrm{O}$ facto da nota de candidatura representar, em grande medida, a qualidade do percurso escolar anteriormente percorrido, e das classificações escolares do $1^{\circ}$ ano serem atravessadas, também, por estas variáveis, vem salientar uma certa continuidade e homogeneidade nos trajectos escolares dos estudantes em estudo. 
Relativamente às variáveis que nos permitem inferir sobre o modo como se processa a transição para ao Ensino Superior, avaliadas através de algumas dificuldades percepcionadas pelos alunos, os obstáculos mais frequentemente referenciados giram em torno das dificuldades de aprendizagem e do relacionamento com colegas. Segue-se a percepção de dificuldades económicas, de organização das tarefas escolares e de relacionamento com os professores. Apesar das diferentes metodologias utilizadas e de algumas especificidades manifestadas, estes índices aproximam-se dos encontrados noutros países (Boyer et al., 2001; Pereira, 2003; Reay et al., 2005), deixando antever alguma homogeneidade na forma de encarar a transição para o Ensino Superior. Por exemplo, tal como num estudo realizado em França (Boyer et al., 2001) maiores dificuldades de aprendizagem são percepcionadas pelos alunos do sexo masculino e por aqueles que apresentam um rendimento académico mais baixo. As maiores dificuldades de aprendizagem antecipadas nos estudantes que frequentam os cursos de engenharias e das ciências económicas podem relacionar-se, quer com a novidade das matérias universitárias abordadas, quer com os discursos difundidos de maior exigência por parte dos professores destes cursos. Esta situação vê-se ainda reforçada pelo facto dos alunos destes cursos referenciarem, igualmente, maiores dificuldades na relação com professores.

A antecipação de algumas dificuldades no relacionamento com os colegas apresenta algumas configurações interessantes. As alunas antecipam maiores dificuldades a este nível que os seus colegas do sexo masculino, o que parece sugerir, de forma consistente com a literatura no domínio, mais dificuldades das alunas nas questões relativas à autonomia nas relações com os outros, mostrando-se mais autónomas nas questões instrumentais relativas ao estudo e às tarefas do dia-a-dia, e/ou mostrando um menor investimento no plano relacional (Boyer et al., 2001; Greeley \& Tinsley, 1988; Mather \& Winston, 1998; Soares, Almeida, \& Ferreira, 2002; Taub, 1997). Simultaneamente, são os alunos que apresentam notas de candidatura ao Ensino Superior mais elevadas, e que conseguiram obter as classificações mais elevadas no final do $1^{\circ}$ ano, os que igualmente percepcionam maiores problemas a este nível. Estes dados podem ser compreendidos se considerarmos, como refere Astin (1993), que os alunos com maiores classificações académicas podem estar mais empenhados na prossecução das suas tarefas escolares, o que pode diminuir ou dificultar as suas relações com os grupos de pares. Adicionalmente, o facto deste tipo de dificuldades se encontrar em maior evidência nos estudantes que frequentam cursos nas áreas de ciências sociais e económicas, e destes cursos serem igualmente frequentados por um maior número de estudantes do sexo feminino, levanos a considerar a possibilidade deste aspecto poder estar também relacionado com o estereótipo de que o sexo feminino concede maior atenção ao domínio do interpessoal. Esta ilação sai reforçada, aliás, quando se constata que as alunas antecipam, também, maiores dificuldades no relacionamento com os professores. Tudo isto parece significar que, na nossa sociedade, o interesse pelas questões interpessoais continuam a ser um indicador associado ao "feminino" (Biaggio, Vikan, \& Camino, 2005; Del Prette et al., 2004; Ferreira, Almeida, \& Soares, 2001), revelado já no estudo clássico de Parsons e Bales (1955), onde os autores opõem a "instrumentalidade" (característica do sexo masculino) à "expressividade" (associada ao sexo feminino).

Por último, a antecipação de dificuldades económicas aparecem associadas aos alunos com notas de candidatura mais reduzidas e oriundos de famílias com menores índices de escolarização, sendo também aqueles que antecipam maiores dificuldades para levar avante o seu projecto académico. Se as dificuldades económicas se entendem no quadro da associação lógica entre níveis de formação académicas dos pais e rendimento sócio-económico da família, o maior número de dificuldades antecipadas na transição pode reflectir o maior desfasamento entre as suas condições anteriores e actuais de vida, assim como o facto de serem maioritariamente alunos de $1^{a}$ geração em termos de Ensino Superior, o que traduzirá, também, um maior desconhecimento do funcionamento das instituições e dos seus contextos. Da mesma forma, e dada a sua origem sócio-familiar, poderão ser alunos que antecipam mais dificuldades em levar avante o seu projecto profissional (Reay et al., 2005) ou que menos se identificam e valorizam a formação académica superior (Machado et al., 2003).

Neste contexto, os resultados deste estudo são consistentes com os de outras investigações, sugerindo que as escolhas dos estudantes pelos diferentes cursos superiores jogam um papel determinante na reconstituição e reprodução das hierarquias sociais estabelecidas. Com efeito, a abertura generalizada e a aparente democratização do acesso ao Ensino Superior acabam por integrar diferenciações relativamente aos trajectos escolares anteriores, à escolha do curso e às taxas de sucesso associadas ao género e à origem sócio-cultural dos estudantes.

\section{Referências}

Almeida, L. S., \& Soares, A. P. (2003). Os estudantes universitários: Sucesso escolar e desenvolvimento psicossocial. In E. Mercuri \& S. A. J. Polydoro (Eds.), Estudante universitário: Características e experiências de formação (pp. 15-40). Taubaté, SP: Cabral Universitária.

Almeida, L. S., Soares, A. P., \& Ferreira, J. A. (2001). Adaptação, rendimento e desenvolvimento dos estudantes no Ensino Superior: Construção do Questionário de Vivências Académicas. Methodus, 5, 3-20.

Almeida, L. S., Vasconcelos, R., Machado, C., Soares, A. P., \& Morais, N. (2002). Perfil escolar e sócio-demográfico dos candidatos ao Ensino Superior: O caso dos estudantes da Universidade do Minho. In A. S. Pouzada, L. S. Almeida, \& Vasconcelos, R. M. (Eds.), Contextos e dinâmicas da vida académica (pp. 219-230). Guimarães, Portugal: Universidade do Minho, Conselho Académico.

Astin, A. (1993). What matters in college? Four critical years revised. San Francisco: Jossey-Bass.

Ball, S. J., Davies, J., David, M., \& Reay, D. (2001). Décisions, différenciations et distinctions: Vers une sociologie du choix des études superieurs. Revue Française de Pédagogie, 136, 65-75. 
Balsa, C. Simões, J. A., Nunes, P., Carmo, R., \& Campos R. L. (2001). Perfil dos estudantes do Ensino Superior: Desigualdades e diferenciação. Lisboa, Portugal: CEOS, Edições Colibri.

Betz, N. E., \& Hackett, G. (1997). Applications of self-efficacy theory to the career development of women. Journal of Career Assessment, 5, 383-402.

Biaggio, A., Vikan, A., \& Camino, C. (2005). Social orientation, sexual role, moral judgment: A comparison of two brazilian and one norwegian sample. Psicologia: Reflexão e Crítica, 18(1), $1-6$.

Boyer, R., Coridian, C., \& Erlich, V. (2001). L’entrée dans la vie étudiante: sócio-culturalisation et apprentissages. Revue Française de Pédagogie, 136, 97-105.

Braga da Cruz, M., Cruzeiro, M. E., Ramos, A., Leandro, E., Nunes, J. S., Matias, N., \& Pedroso, P. et al. (1995). O desenvolvimento do Ensino Superior em Portugal: Situação e problemas de acesso. Lisboa, Portugal: Ministério da Educação, Departamento de Programação e Gestão Financeira.

Cabrito, B. G. (2001). Universidade e reprodução sócio-cultural. Revista de Educação, 1O(2), 25-37.

Castro, A, P. E., \& Yamamoto, O. H. (1998). Psychology as a feminine career: Notes for a study. Estudos de Psicologia, 3(1), 147-158.

Chickering, A. W., \& Reisser, L. (1993). Education and identity. San Francisco: Jossey-Bass.

Dawson-Threat, J., \& Huba, M. E. (1996). Choice of major and clarity purpose among college seniors as a function of gender, type of major, and sex-role identification. Journal of College Student Development, 37, 297-308.

Del Prette, Z. A. P., Del Prette, A., Barreto, M. C. M., Bandeira, M., Rios-Saldaña, M. R., Ulian, A. L. A. O., \& Gerk-Carneiro, E. et al. (2004). Social skills of psychology undergraduate: A multicentered study. Psicologia: Reflexão e Crítica, 17(3), 341350.

Duru-Bellat, M. (2000). Sócio-cultural inequalities in the French education system: The joint effect of individual and contextual factors. Journal of Education Policy, 15(1), 33-40.

Egerton, M., \& Halsey, A. H. (1993). Trends by sócio-cultural class and gender in access to higher education in Britain. Oxford Review of Education, 19(2), 183-196.

Eurydice. (2003). Key data on education in Europe 2002. Bruxelas, Bélgica: Comissão Europeia.

Ferreira, J. A., Almeida, L. S., \& Soares, A. P. (2001). Adaptação académica em estudantes do $1^{\circ}$ ano: Diferenças de género, situação de estudante e curso. PsicoUSF, 6, 1-10.

Gago, J. M., Amaral, J. F., Grácio, S., Rodrigues, M. J., Fernandes, L., Ruivo, B., \& Ambrósio, T. et al. (1994). Prospectiva do Ensino Superior em Portugal. Lisboa, Portugal: Ministério da Educação, Departamento de Programação e Gestão Financeira.

Gianakos, I., \& Subich, L. M. (1988). Student sex and sex role in relation to college major choice. Career Development Quarterly, 36, 259-268.

Gottfedson, L. S. (1981). Circumscription and compromise: A developmental theory of occupational aspirations. Journal of Counseling Psychology, 28, 545-579.

Greeley, A., \& Tinsley, H. (1988). Autonomy and intimacy development in college students: Sex differences and predictors. Journal of College Student Development, 29, 512-520.

Hackett, G., Betz, N., Casas, J. M., \& Rocha-Singh, I. A. (1992). Gender, ethnicity, and social cognitive factors predicting the academic achievement of students in engineering. Journal of Counseling Psychology, 39, 527-538.
Hansen, S. S. (2003). Career counsellors as advocates and change agents for equality. The Career Development Quarterly, 52, 43-53.

Hatcher, R. (1998). Class differentiation in education: Rational choices? British Journal of Sociology of Education, 19(1), 5-24.

Lackland, A. C., \& DeLisi, R. (2001). Students' choices of college majors that are gender traditional and non-traditional. Journal of College Student Development, 42, 39-47.

Lent, R. W., Brown, S. D., \& Hackett, G. (1994). Toward a unifying social cognitive theory of career and academic interest, choice, and performance. Journal of Vocational Behavior, 45, 79-122.

Machado, F. L., Costa, A. F., Mauritti, R., Martins, S. C., Casanova, J. L, \& Almeida, J. F. (2003). Classes sociais e estudantes universitários: Origens, oportunidades e orientações. Revista Crítica de Ciências Sociais, 66, 45-80.

Mather, J. C., \& Winston, R. B. (1998). Autonomy development of traditional-aged students: Themes and processes. Journal of College Student Development, 39, 33-50.

Mercuri, E. N. G. S., \& Polydoro, S. A. (2003). O compromisso com o curso no processo de permanência/evasão no ensino superior: Algumas contribuições. In E. Mercuri \& S. A. J. Polydoro (Eds.), Estudante universitário: Características e experiências de formação (pp. 219-236). Taubaté, SP: Cabral Universitária.

Parsons, T., \& Bales, R. F. (1955). Family, socialization and interaction process. New York: Free Press.

Pascarella, E. T., \& Terenzini, P. T. (2005). How college affects students: A third decade of research. San Francisco: Jossey-Bass.

Pereira, E. M. A. (2003). A percepção dos universitários sobre seus problemas. In E. Mercuri \& S. A. J. Polydoro (Eds.), Estudante universitário: Características e experiências de formação (pp. 187-217). Taubaté, SP: Cabral Universitária.

Pinto, J. M. R. (2004). O acesso à educação superior em Brasil. Educação \& Sociedade, 25, 727-756.

Reay, D., David, M. E., \& Ball, S. J. (2005). Degrees of Choice: Class, Gender and Race in the Higher Education choice process. London: Trentham Books.

Saavedra, L., Almeida, L. S., Gonçalves, A., \& Soares, A. P. (2004). Pontos de partida, pontos de chegada: Impacto de variáveis sócio-culturais no ingresso ao ensino superior. Cadernos do Noroeste, 22(1-2): Vol. 6. Sociologia, sociedade e cultura (pp. 6384). Braga, Portugal: Instituto de Educação e Psicologia, Universidade do Minho.

Soares, A. P. (2003). Transição para o Ensino Superior: Construção e validação de um modelo multidimensional de ajustamento de jovens ao contexto universitário. Dissertação de Doutorado, Universidade do Minho, Instituto de Educação e Psicologia, Braga, Portugal.

Soares, A. P., Almeida, L. S., \& Ferreira, J. A. (2002). Contributos para a avaliação do Inventário de Desenvolvimento da Autonomia de Iowa com estudantes universitários portugueses. Revista Psicologia e Educação, 1-2, 91-106.

Surtees, P. G., Wainwright, N. W. J., \& Pharoah, P. D. P. (2002). Psychosócio-cultural factors and sex differences in high academic attainment at Cambridge University. Oxford Review of Education, 28, 21-38.

Taub, D. (1997). Autonomy and parental attachment in traditionalage undergraduate women. Journal of College Student Development, 38, 645-65 1.

Vermetten, Y. J., Vermunt, J. D., \& Lodewijks, H. G. (1999). A longitudinal perspective on learning strategies in Higher Education: Different viewpoints towards development. British Journal of Educational Psychology, 69, 221-235. 